\title{
ESTIMATION OF SOME SECONDARY METABOLITES FROM THE IN VITRO CULTURES OF CHLOROPHYTUM BORIVILIANUM SANT. Et. FERN
}

\author{
JHA A., BANSAL Y. K. ${ }^{*}$ \\ Department of Biological Science, R. D. University, Jabalpur (M. P.) 482001 \\ Email: jha.aprajita@gmail.com
}

Received: 16 May 2017 Revised and Accepted: 22 Nov 2017

\begin{abstract}
Objective: To perform phytochemical screening, estimate total saponins and to study the secondary metabolite profiling of Chlorophytum borivilianum by ESI-MS (Electron spray ionisation-mass spectroscopy) and GC-MS (Gas chromatography-mass spectroscopy) techniques.

Methods: The powdered samples of leaves and roots (nature grown and freshly harvested and hardened in vitro regenerated) and callus of Chlorophytum borivilianum ( $2 \mathrm{~g}$ ) were extracted exhaustively by soxhlet by refluxing with petroleum ether $\left(60-80^{\circ} \mathrm{C}\right)$ and then with ethanol $(85 \%)$. Alternatively, the methanol extract was prepared for the samples by the cold maceration method and the filtered extract was used. This extract was further analyzed by gas chromatography-mass spectrometry to identify and characterize the chemical compounds present in the crude extracts.
\end{abstract} Vanillin sulphuric acid assay was done to estimate the total saponin content of extracts.

Results: Phytochemical analysis of ethanolic extract showed the presence of major classes of phytochemicals. The spectrophotometric analysis as well as the GC-MS results revealed the remarkably high percentage of saponin content in the in vitro roots. Besides this, many important secondary metabolites viz. $\beta$-Sitosterol and Taraxerone were also revealed by GC-MS.

Conclusion: Results of this study showed enhanced production of many important secondary metabolites, especially saponins in tubers of in vitro regenerated plantlets vis a vis that of the nature grown plants establishing the fact that micropropagation can pave new vistas for the research in phytopharmaceuticals and bioprospecting of rare and important medicinal plants.

Keywords: Chlorophytum borivilianum, Phytochemical, ESIMS, GCMS, In vitro cultures

(C) 2018 The Authors. Published by Innovare Academic Sciences Pvt Ltd. This is an open access article under the CC BY license (http://creativecommons.org/licenses/by/4.0/) DOI: http://dx.doi.org/10.22159/ijpps.2018v10i1.20757

\section{INTRODUCTION}

Since the dawn of mankind, plants with secondary metabolites have been used to treat human infections and diseases. Pharmaceutically significant secondary metabolites or phytopharmaceuticals include alkaloids, glycosides, flavonoids, volatile oils, tannins, resins etc. Currently, most of these secondary metabolites are either isolated from wild or cultivated plants, as their chemical synthesis is either extremely difficult or economically infeasible. Biotechnological production in plant cell cultures is an attractive alternative, but till recently it has had only limited commercial success due to the lack of understanding of how these metabolites are synthesized [1].

Chlorophytum borivilianum Santapau and Fernandes is a small perennial herb belonging to the family Liliaceae. The plant is indigenous to the forests of Rajasthan, western M. P. and north Gujarat. The tubers of this plant are highly reputed for its adaptogenic and aphrodisiac properties $[2,3]$. The tubers are particularly rich in steroidal and tri-terpenoidal saponins, alkaloids, vitamins, minerals, proteins, polysaccharides and steroids. It also contains fructans, simple sugars such as glucose and fructose, phenolics, triterpenoids, gallo-tannins and mucilage [4-6]. Because of the great therapeutic importance, $C$. borivilianum tubers are the major constituents of more than a hundred ayurvedic preparations [7]. Attributing to its medicinal properties the demand for $C$. borivilianum tubers has bolstered across the world and India has been a huge market for it [8]. The ever-growing market demand coupled with the over exploitation of this plant has dwindled the population of $C$. borivilianum in its natural habitat [9].

There are a few reports on tissue culture based propagation of Chlorophytum borivilianum [10-12]. Albeit there has been a paucity of scientific work regarding the efficient phytochemical investigations from the in vitro raised cultures of this plant. Therefore, the estimation of secondary metabolites of $C$. borivilianum in the present investigation proceeded using a combination of various techniques viz. TLC, spectrophotometric (colorimetric) estimation, HPLC, ESI-MS and GC-MS analysis.

\section{MATERIALS AND METHODS}

\section{Culture media and growth conditions}

The plant material was obtained in the form of dry C. borivilianum tubers from Jawaharlal Nehru Agriculture University, Jabalpur (India). The young, shoot bud sprouts on the surface of dried tubers during monsoons were used as explants. After the initial procedure of surface sterilization, the explants were aseptically transferred to Murashige and Skoog (MS) medium supplemented with $3 \%(\mathrm{w} / \mathrm{v})$ sucrose, $0.8 \%$ $(\mathrm{w} / \mathrm{v})$ agar and fortified with different concentrations of PGRs. The $\mathrm{pH}$ of the media was adjusted to $5.6-5.8$ before adding agar $\left(8 \mathrm{gm} \mathrm{L}^{-1}\right)$. The media was sterilized at $15 \mathrm{lbs}$ pressure for $15 \mathrm{~min}$ by autoclaving. Cultures were incubated at $25 \pm 2{ }^{\circ} \mathrm{C}$ at photoperiodic cycle of $16 \mathrm{hr}$ light (approx. 1500 lux) and $8 \mathrm{hr}$ dark. All cultures were sub-cultured on the fresh medium at every four-week interval. In vitro response from each explant was recorded every week.

\section{Somatic embryo induction and development}

The juvenile shoot bud explants were inoculated on MS medium supplemented with varying concentrations $(0.1,0.5,1$ and $5 \mathrm{mg} / \mathrm{l})$ of $\mathrm{BAP}$ and $\mathrm{KN}$ alone. BAP at $5 \mathrm{mg} / \mathrm{l}$ concentration was able to induce a very high frequency of somatic embryogenesis (80.55) with an average of 18.44 embryos per explants. On the other hand, a much lower concentration of BAP $(0.5 \mathrm{mg} / \mathrm{l})$ led to the proliferation of somatic embryos. For the multiplication and growth of somatic embryos, the embryos were next sub-cultured on MS medium supplemented with varying concentrations $(0.1,0.5,1$ and $5 \mathrm{mg} / \mathrm{l})$ of $\mathrm{BAP}$ and $\mathrm{KN}$ alone and in combination, whereas, the hormone free medium i.e. basal medium (BM) served as control. The conversion of somatic embryos with high MRN and MRL was favoured on BM [13].

\section{Preparation of plant samples}

Both nature grown and hardened in vitro regenerated plants were collected and washed thoroughly under running tap water and allowed to dry for some time. The leaves and roots were separated 
and shade dried without any contamination for about 3 to $4 \mathrm{w}$. The dried plant samples were powdered in a blender and stored in airtight containers.

\section{Preparation of extracts}

\section{Ethanolic extract}

The powdered samples of leaves and roots (nature grown and freshly harvested and hardened in vitro regenerated) and callus (2g) were extracted exhaustively by refluxing with petroleum ether $\left(60-80{ }^{\circ} \mathrm{C}\right)$ and then with ethanol (85\%) in a soxhlet apparatus. The ethanolic extracts were concentrated and used further.

\section{Methanolic extract}

Alternatively, the powdered samples of leaves and roots (nature grown and hardened in vitro regenerated) and callus (2g) were extracted in methanol by cold maceration method. The extract was filtered and the filtrate was further used for analysis.

\section{Extraction and isolation of saponins}

After evaporation of the ethanolic extract, the gummy residue was suspended in $\mathrm{H}_{2} \mathrm{O}(100 \mathrm{ml})$ and extracted with n-butanol $(300 \mathrm{ml})$. The n-butanol fraction was reduced to half and washed twice with $10 \mathrm{ml}$ of $5 \% \mathrm{NaCl}$ solution to yield crude saponin fraction $[14,15]$.

\section{Preliminary phytochemical screening of plant extracts}

Phytochemical screening was performed for the analysis of different phytochemicals like carbohydrates, saponins, oils, fats, flavonoids, terpenoids, alkaloids etc., in methanolic extracts of plant samples. The screening was performed with some modifications from the methods of Harborne [16] and Evans [17].

\section{Estimation of saponins by vanillin-sulfuric acid assay}

The method described by Hiai et al. [18] was adopted. To $0.5 \mathrm{ml}$ of aqueous solution of the sample, $0.5 \mathrm{ml}$ vanillin solution of $8 \%(\mathrm{w} / \mathrm{v})$ and then $5.0 \mathrm{ml}$ of sulfuric acid of $72 \%(\mathrm{w} / \mathrm{v})$ were added and thoroughly mixed in an ice water bath. The mixture was then warmed in a bath at $60^{\circ} \mathrm{C}$ for $10 \mathrm{~min}$ and then cooled in ice-cold water. Absorbance at $535 \mathrm{~nm}$ was recorded against the blank with the reagents using UV/VIS spectrophotometer (Systronics UV-VIS Spectrophotometer; 108).

\section{Thin layer chromatography (TLC)}

Silica gel G, $F_{254}, 20 \mathrm{~cm} \times 20 \mathrm{~cm}$ plates were used for thin layer chromatography. The extracts of calli as well as the leaves and roots of nature grown and in vitro regenerated plants obtained were applied to activated plates and were placed in different solvent systems (table 1) for the detection of secondary metabolites. The developed chromatograms were observed under UV light and their Rfs were calculated.

Table 1: Solvent systems used for different metabolites

\begin{tabular}{lll}
\hline S. No. & Secondary metabolites & Solvent systems \\
\hline 1. & Saponins & Chloroform-methanol-water $(60: 30: 10)$, chloroform-Gl. acetic acid-methanol- \\
2. & & water $(16: 8: 3: 2)$ and n-hexane-ethyl acetate $(9: 1)$. \\
3. & Flavonoids & Ethyl acetate-Gl. acetic acid-methanol-water $(100: 11: 11: 26)$ \\
\hline
\end{tabular}

\section{High-performance liquid chromatography (HPLC)}

The HPLC method was used to estimate the presence saponins in the natural and hardened in vitro regenerated leaves and roots, freshly harvested in vitro regenerated root and callus. Saponins of $C$. borivilianum were detected with the help of retention time compared with the standard (Saponin from Sigma Aldrich-47036). The fraction analysis was carried out in a Dionex model $\mu$ HPLC Focus Ultimate 300 having a pore size of $5 \mu$. A C 18 RP Column (150 x $4.6 \mathrm{~mm}$ I.D.) was used at a temperature of $30^{\circ} \mathrm{C}$.

A Linear gradient of acetonitrile: water (4:6 to 6:4) over 30 min was used and the mixture was degassed and filtered [19]. The flow rate was maintained at $1 \mathrm{ml}$ per minute. The detection was done in $\mathrm{UV}$ at $200-400 \mathrm{~nm}$.

\section{Electron spray ionisation-mass spectroscopy (ESI-MS)}

The ESI-MS analysis of the above samples that were subjected to HPLC was performed on Bruker micrOTOF-Q II 10348, mass spectrophotometer equipped with an ESI source in a positive ion mode. High purity nitrogen gas was used as collision, nebulizer and auxillary heated gas. The ESI conditions were set as follows: spray voltage $+4500 \mathrm{~V}$; nebulizer gas flow, $4.0 \mathrm{l} / \mathrm{min}$; temperature, $180^{\circ} \mathrm{C}$.

\section{Gas chromatography-mass spectroscopy (GC-MS)}

The methanolic extracts of nature grown and hardened in vitro roots and callus, obtained by cold maceration method were subjected to GC-MS analysis. The analysis was performed on Shimadzu QP-2010 plus with Thermal Desorption System. The MS scan range was 40650 atomic mass units (AMU). The chromatographic column was fused silica RTX-5MS (95\% dimethlpolysiloxane - 5\% diphenyl) capillary column $(30 \mathrm{~m} \mathrm{X} 0.25 \mathrm{~mm}$ i.d. X0.25 $\mu \mathrm{m})$. The carrier gas used was helium at a flow rate of $1.21 \mathrm{ml} / \mathrm{min}$. Samples were analyzed with the column held initially at $100{ }^{\circ} \mathrm{C}$ for $2 \mathrm{~min}$. and then increased to $280^{\circ} \mathrm{C}$ with $15^{\circ} \mathrm{C} / \mathrm{min}$ heating rate and a hold time of $20 \mathrm{~min}$. The injection was performed in a split mode at $250^{\circ} \mathrm{C}$. The identification of individual compounds was done from Wiley and NIST mass spectral library on the basis of mass fragments and $\mathrm{m} / \mathrm{z}$ values of each component.

\section{RESULTS}

\section{Phytochemical screening of plant extracts}

The curative properties of medicinal plants are due to the presence of various secondary metabolites such as alkaloids, flavonoids, glycosides, phenols, saponins, sterols etc. The extracts of hardened in vitro and nature grown leaves and roots revealed the presence of carbohydrates, proteins, saponins, flavonoids, cardiac glycosides and gums and mucilaginous substances (table 2). Thus the preliminary screening tests may be useful in the detection of the bioactive principles and subsequently may lead to the drug discovery and development.

\section{Estimation of Saponin content by vanillin-sulphuric acid assay}

Linearity was evident for the regression in the standard saponin (Sigma Aldrich) contents by the vanillin-sulphuric acid assay. The total absorption was observed at $535 \mathrm{~nm}=0.2462 \mathrm{x}$ saponin content $(\mathrm{mg} / \mathrm{ml})+0.009, \mathrm{R}^{2}=0.9835$. On this basis, it was observed that the roots of the freshly harvested in vitro regenerated and hardened plants possessed the highest amount of saponin $(1.9 \mathrm{mg} / \mathrm{ml})$ as compared to the nature grown ones $(0.77 \mathrm{mg} / \mathrm{ml})$.

This was followed by the callus obtained using the combination of varying concentrations of KN and 2, 4-D in MS medium $(1.11 \mathrm{mg} / \mathrm{ml})$ (table 3). Therefore, the callus obtained from MS+KN+2,4-D combination was further used for analysis. 
Table 2: Preliminary phytochemical analysis of plant extracts

\begin{tabular}{|c|c|c|c|c|}
\hline & \multicolumn{2}{|l|}{ Root } & \multicolumn{2}{|l|}{ Leaves } \\
\hline & Nature grown & Hardened in vitro & Nature grown & Hardened in vitro \\
\hline Carbohydrates (Molisch test) & + & + & + & + \\
\hline Proteins (Biuret test) & + & + & + & + \\
\hline Saponin (Foam test) & + & + & - & - \\
\hline Cardiac glycosides & + & + & - & - \\
\hline Oils and fats & - & - & + & + \\
\hline Anthocyanins & - & - & + & + \\
\hline Terpenoids & + & + & - & - \\
\hline Alkaloids & - & - & + & + \\
\hline Flavonoids & + & + & + & + \\
\hline Sterols & + & + & + & + \\
\hline Tannins and Phenols & - & - & + & + \\
\hline Gums and mucilage & + & + & - & - \\
\hline
\end{tabular}

$(+)=$ present, $(-)=$ absent

Table 3: Saponin content estimation by vanillin-sulphuric acid assay

\begin{tabular}{ll}
\hline Samples (Aq. extracts) & Amount of saponin (mg/ml) \\
\hline Hardened In vitro roots & $\mathbf{1 . 9 \pm 0 . 0 4}$ \\
Nature grown roots & $0.77 \pm 0.03$ \\
Freshly harvested in vitro roots & $0.55 \pm 0.02$ \\
MS+2, 4-D callus & $0.04 \pm 0.01$ \\
MS+IAA callus & $0.59 \pm 0.01$ \\
MS+IBA callus & $0.52 \pm 0.02$ \\
MS+NAA callus & $0.02 \pm 0.01$ \\
MS+KN+2, 4-D callus & $\mathbf{1 . 1 1} \pm \mathbf{0 . 1 1}$ \\
MS+BAP+2, 4-D callus & $0.61 \pm 0.03$ \\
MS+KN+NAA callus & $0.28 \pm 0.02$ \\
MS+BAP+NAA callus & $0.29 \pm 0.02$ \\
\hline
\end{tabular}

Results are represented as mean $( \pm$ standard error) of three independent readings, $\mathrm{P}<0.05$.

\section{Thin layer chromatography (TLC)}

The TLC analysis of hardened in vitro and nature grown roots showed the presence of saponins, flavonoids and alkaloids. The callus showed identical Rfs corresponding to that of the standard and hardened in vitro regenerated and nature grown roots for saponins (0.73) and alkaloids (0.98) however, it failed to show up any corresponding Rfs for flavonoids, when compared with the standards (table 4, fig. 1-4).

Table 4: TLC of the callus and nature grown and hardened in vitro regenerated roots of Chlorophytum borivilianum

\begin{tabular}{lllll}
\hline $\begin{array}{l}\text { Secondary } \\
\text { metabolite }\end{array}$ & Solvent system & \multicolumn{2}{l}{ Rf values } \\
\cline { 2 - 4 } & & S & C & NR \\
\hline Saponins & n Hex: $\operatorname{EtAc}(9: 1)$ & 0.73 & $0.73,0.58,0.56,0.52,0.44,0.22$ & $0.73,0.58,0.56$ \\
& $\mathrm{CHCl}_{3}: \mathrm{CH}_{3} \mathrm{OH}: \mathrm{H}_{2} \mathrm{O}(60: 30: 10)$ & 0.96 & - & $0.73,0.58,0.56$ \\
Alkaloids & EtAc: $\mathrm{CH}_{3} \mathrm{OH}: \mathrm{H}_{2} \mathrm{O}(10: 1.35: 1)$ & 0.98 & 0.98 & 0.93 \\
Flavonoids & EtAc: Formic acid: GAA: $\mathrm{H}_{2} \mathrm{O}(100: 11: 11: 26)$ & 0.9 & - & 0.95 \\
\end{tabular}

$\mathrm{NR}=$ Nature-grown root, $\mathrm{IVR}=$ In vitro regenerated root, $\mathrm{C}=$ Callus, $\mathrm{S}=$ standard

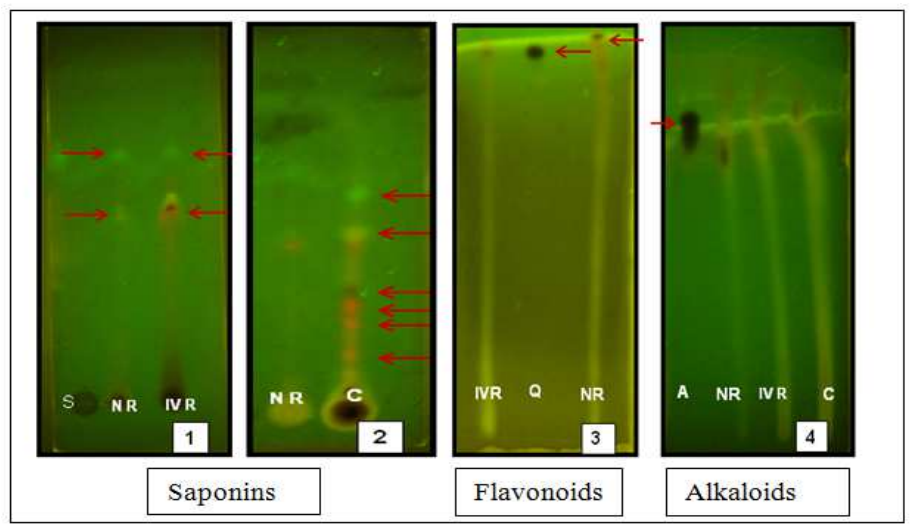

Fig. 1-4: TLC of root samples and callus, $S=$ saponin standard, $I V R=$ in vitro root, $N R=$ nature grown root, $C=$ callus, $Q=$ quercitin (flavonoid standard), A = colchicine (alkaloid standard) 


\section{High-performance liquid chromatography (HPLC)}

The HPLC analysis of the test tube grown roots, callus as well as nature grown and hardened in vitro regenerated roots showed an identical Retention time (RT) of 2.10 as compared that of standard saponin (Sigma Aldrich). Other common peaks were also found in the test tube grown roots, callus and nature grown and hardened in vitro regenerated roots that were not observed in the standard saponin. The callus and hardened in vitro regenerated and nature grown roots showed similar RTs at 2.28, 2.26 and 2.27 respectively. Identical peaks at RT 2.98 and 2.95 for the hardened in vitro regenerated and nature grown roots were also observed (fig. 5-7).

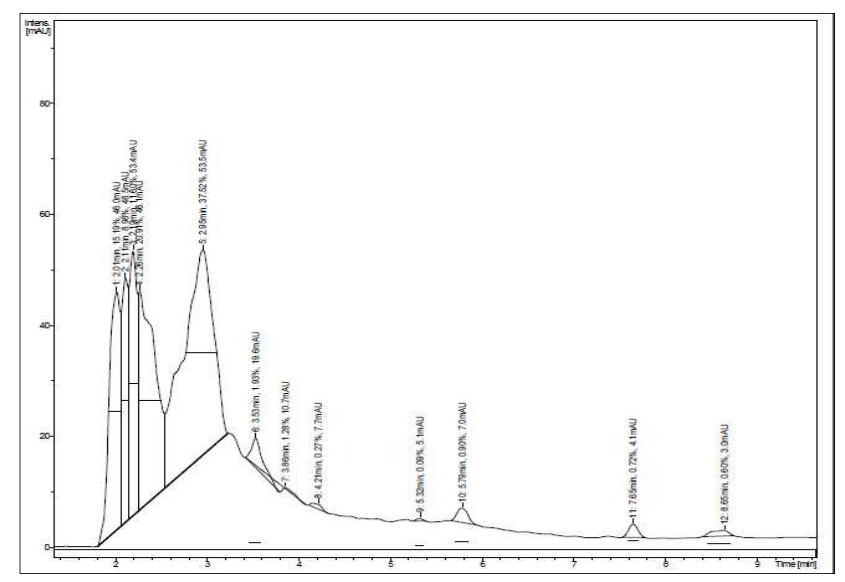

Fig. 5: HPLC of nature grown roots

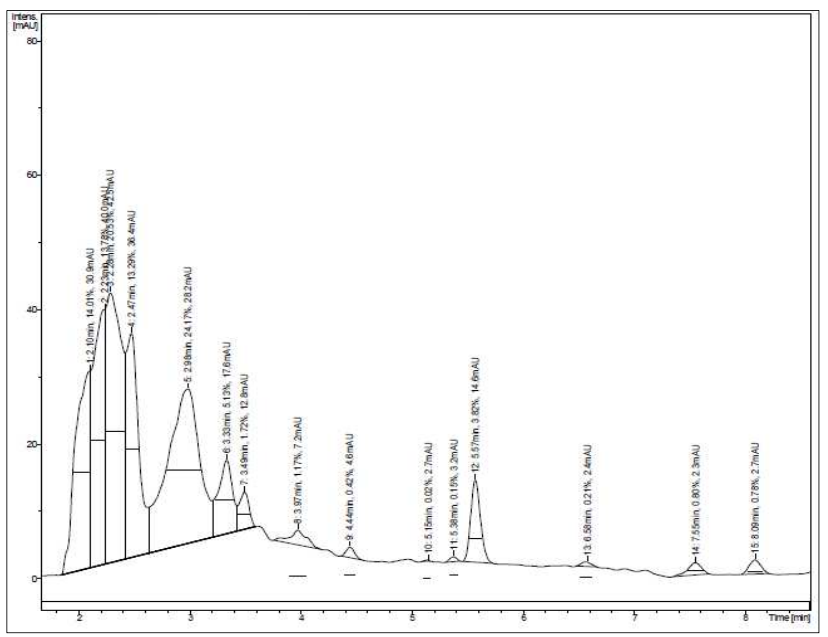

Fig. 6: HPLC of in vitro regenerated roots

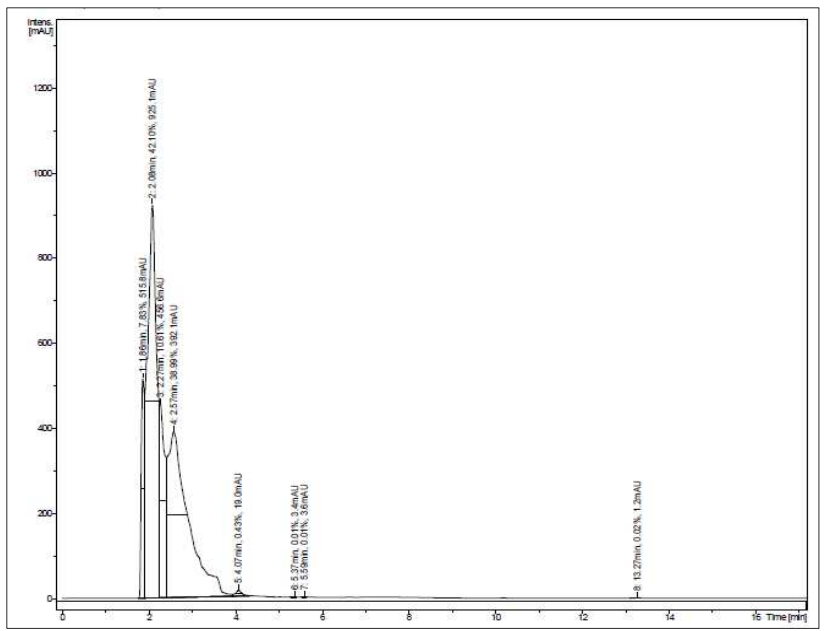

Fig. 7: HPLC of callus 


\section{Electron spray ionisation-mass spectroscopy (ESI-MS)}

Under the ESI-QTOF-MS the steroidal saponins of $C$. borivilianum were easily ionized and showed the presence of molecular species in the positive ion mode. By comparing the high-resolution mass data based on individual $\mathrm{m} / \mathrm{z}$ values a good number of discernable peaks were obtained in the roots and leaves of in vitro regenerated and nature-grown plants and also in the callus and test-tube grown tubers. Among the vast array of $\mathrm{m} / \mathrm{z}$ data of the above-mentioned samples, many peaks were found in common. A list of common peaks is summarized in table 5 .

Since steroidal saponins are the principle compounds present in the plant under study, the fragmentation pattern of steroidal saponins was taken under review. Based on the literature surveyed the substituents on the steroidal aglycone moiety are observed. If these data are not available then the diagnostic ions at $\mathrm{m} / \mathrm{z} 253$ and 271 must be taken under consideration. If the above diagnostic ions are still not detected, this indicates that the saponin possesses a transformed aglycone as dioscorioside A. Furthermore, the aglycone ion can be viewed as the indicator to know whether the steroidal saponins are substituted or not. If ion at $\mathrm{m} / \mathrm{z} 415$ was present no substituent should be attached to the aglycone; on the other hand, if ion at $\mathrm{m} / \mathrm{z} 413$ was detected, there should be a substituent on the steroid aglycone.
The mass spectra of callus and hardened in vitro regenerated and nature-grown roots thus showed identical peaks at $\mathrm{m} / \mathrm{z} 413$ which suggested that there was a substitution at the aglycone ion, which upon observation sufficed the probable molecular formula of the aglycone to be $\mathrm{C}_{27} \mathrm{H}_{47} \mathrm{O}_{3}{ }^{+}$. The said aglycone lost a water molecule to yield another fragmentation product at $\mathrm{m} / \mathrm{z} 395$, which was again observed in the callus and hardened in vitro root sample.

Thus based on the intense proton adduct ion $[\mathrm{M}+\mathrm{H}]^{+}$of the hardened in vitro root saponin at $\mathrm{m} / \mathrm{z} 533$ in positive ion mode, the proposed fragmentation would be as follows; m/z $533[\mathrm{M}+\mathrm{H}]^{+}, \mathrm{m} / \mathrm{z} 517[\mathrm{M}+\mathrm{H}-$ $\left.\mathrm{H}_{2} \mathrm{O}-2 \mathrm{H}\right]^{+}, \mathrm{m} / \mathrm{z} 497\left[\mathrm{M}+\mathrm{H}-2 \mathrm{H}_{2} \mathrm{O}\right]^{+}, \mathrm{m} / \mathrm{z} 435\left[\mathrm{M}+\mathrm{H}-4 \mathrm{H}_{2} \mathrm{O}\right]^{+}$. As compared to the mass spectra of nature grown root lower $\mathrm{m} / \mathrm{z}$ values in the hardened in vitro regenerated root sample suggested the possibility of loss of glycosides like hexoses and pentoses from it. The proposed fragmentation of the nature grown root sample would be as follows; $\mathrm{m} / \mathrm{z}$

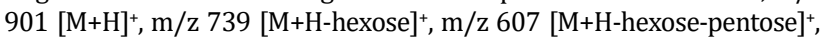
$\mathrm{m} / \mathrm{z} 587$ [M+H-hexose-pentose- $\left.\mathrm{H}_{2} \mathrm{O}\right]^{+}, \mathrm{m} / \mathrm{z} 569$ [M+H-hexose-pentose$\left.\mathrm{H}_{2} \mathrm{O}\right]^{+}, \mathrm{m} / \mathrm{z} 551$ [M+H-hexose-pentose- $\left.2 \mathrm{H}_{2} \mathrm{O}\right]^{+}, \mathrm{m} / \mathrm{z} 533$ [M+H-hexosepentose- $\left.3 \mathrm{H}_{2} \mathrm{O}\right]^{+}, \mathrm{m} / \mathrm{z} 497$ [M+H-hexose-pentose- $\left.5 \mathrm{H}_{2} \mathrm{O}\right]^{+}$.

The fragmentation peak for $\mathrm{m} / \mathrm{z} 533$ is also present in the in vitro regenerated root sample, suggesting the fact that, this molecule is a fragmentation product of a molecule similar to that of nature grown root (fig. 8-10).

Table 5: A list of common $\mathrm{m} / \mathrm{z}$ values obtained from the ESI-MS of the callus and root extracts Chlorophytum borivilianum

\begin{tabular}{llll}
\hline Common m/z values & Saponin standard & Hardened in vitro roots & Nature grown roots \\
\hline 347 & + & + & + \\
367 & + & & + \\
381 & + & + & + \\
395 & + & + & + \\
$413 *$ & + & & + \\
437 & + & + & + \\
497 & + & + & + \\
533 & & + & \\
597 & + & & + \\
613 & & & + \\
615 & & & + \\
616 & & & + \\
631 & & & + \\
633 & & & + \\
655 & & & + \\
701 & & & + \\
893 & & & + \\
917 & & & \\
\hline
\end{tabular}

*Diagnostic $\mathrm{m} / \mathrm{z}$ of steroidal aglycone [20]

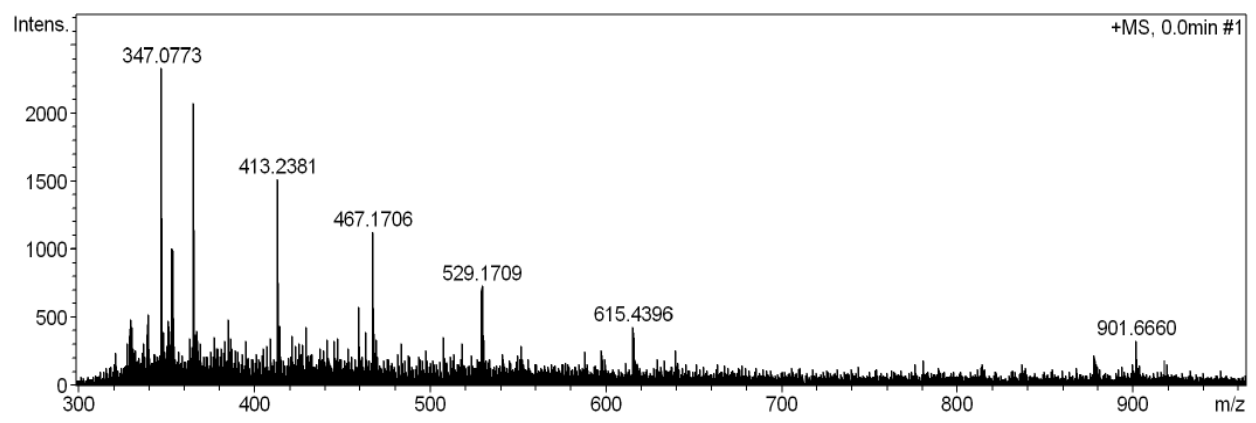

Fig. 8: ESI-MS of nature grown roots of Chlorophytum borivilianum

\section{Gas chromatography-mass spectroscopy}

All the three samples viz; the roots of nature grown and hardened in vitro regenerated plants and callus showed the presence of some of the medicinally important secondary metabolites like Taraxerone, $\beta$ Sitosterol and Lupenol (Triterpene) (table 6). The in vitro roots here showed the highest amount of all the three secondary products, with the remarkably high percentage of $\beta$-sitosterol (8.16\%) and Taraxerone (5.47\%) (fig. 12). The nature grown roots revealed the presence of sarasapogenin (fig. 11). On the other hand hardened in vitro roots showed the presence of squalene; which is an important precursor in the synthesis of steroidal compounds. The callus 
revealed the presence of many important secondary metabolites of high medicinal importance like digitoxin $(0.39 \%)$, $\beta$-carotene $(0.37 \%)$ and gamma sitosterol (1.79) (fig. 13). All the three samples were also found to possess phytosterols like ergosterol and stigmasterol. The hardened in vitro regenerated roots showed a higher amount of ergosterol (2.43\%) which was 9.6 fold and stigmasterol $(8.16 \%)$ to be 51 folds higher than the nature grown ones (fig. 14-16). An appreciable amount of carbohydrateintermediates were observed in the hardened in vitro root and callus extracts. The hardened in vitro root sample revealed the presence of $\alpha$-D-glucopyranoside (8.27\%) and D-Allose (2.07\%). D-Allose was also observed in callus (3.31\%), which was slightly higher as compared to the hardened in vitro root sample. $\beta$-D-galactopyranoside and $\beta$ - $D$ glucopyranose were observed in both the samples.

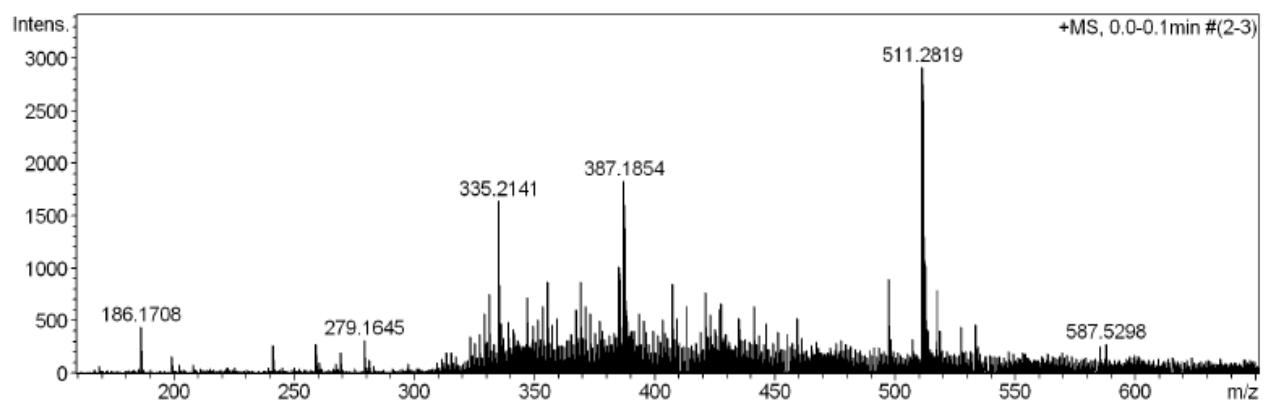

Fig. 9: ESI-MS of in vitro regenerated roots of Chlorophytum borivilianum

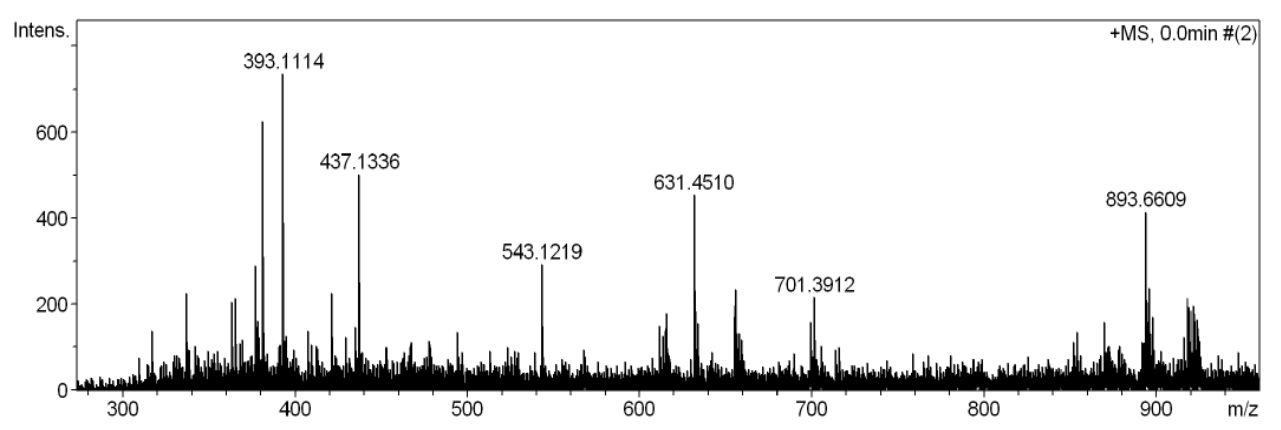

Fig. 10: ESI-MS of callus of Chlorophytum borivilianum

Table 6: A comparative analysis by GC-MS of some major secondary products of the nature grown and hardened in vitro regenerated roots and callus samples of Chlorophytum borivilianum

\begin{tabular}{|c|c|c|}
\hline R time & $\%$ area & Compound name \\
\hline \multicolumn{3}{|c|}{ Nature grown roots } \\
\hline 6.1 & 49.94 & 2-furancarboxaldehyde \\
\hline 29 & 0.71 & Stigmasterol \\
\hline 29.4 & 0.25 & Sarsasapogenin \\
\hline 29.5 & 0.16 & Stigmast-5-en-3-ol, \\
\hline 30.4 & 0.12 & D: A-Friedoolean-6-ene \\
\hline \multicolumn{3}{|c|}{ Regenerated roots } \\
\hline 9.8 & 2.07 & D-allose \\
\hline 11.8 & 8.27 & Ethyl. alpha.-d-glucopyranoside \\
\hline 24.7 & 1.41 & Squalene \\
\hline 25.5 & 5.05 & 1-heptacosanol \\
\hline 27.9 & 1.24 & Cholest-5-en-3-ol (3. beta.)- \\
\hline 28.7 & 2.43 & Ergost-5-en-3-ol \\
\hline 29 & 5.47 & D-friedoolean-14-en-3-one \\
\hline 29.5 & 8.16 & Stigmast-5-en-3-ol \\
\hline \multicolumn{3}{|l|}{ Callus } \\
\hline 4.5 & 8.29 & 4H-Pyran-4-one, 2,3-dihydro-3,5-dihydroxy-6-methyl- \\
\hline 5.8 & 7.59 & 2-Furancarboxaldehyde, 5-(hydroxymethyl \\
\hline 10.2 & 3.31 & D-allose \\
\hline 14.6 & 14.12 & $N$-Hexadecanoic acid \\
\hline 16.3 & 17.09 & 9,12-Octadecadienoic acid \\
\hline 18.3 & 0.34 & Lup-20(29)-ene-3,28-diol \\
\hline 22.2 & 0.39 & Digitoxin \\
\hline 24.8 & 0.37 & Beta. Carotene \\
\hline 29 & 1.56 & Stigmasta-5,22-dien-3-ol \\
\hline 29.4 & 1.79 & Gamma.-sitosterol \\
\hline
\end{tabular}




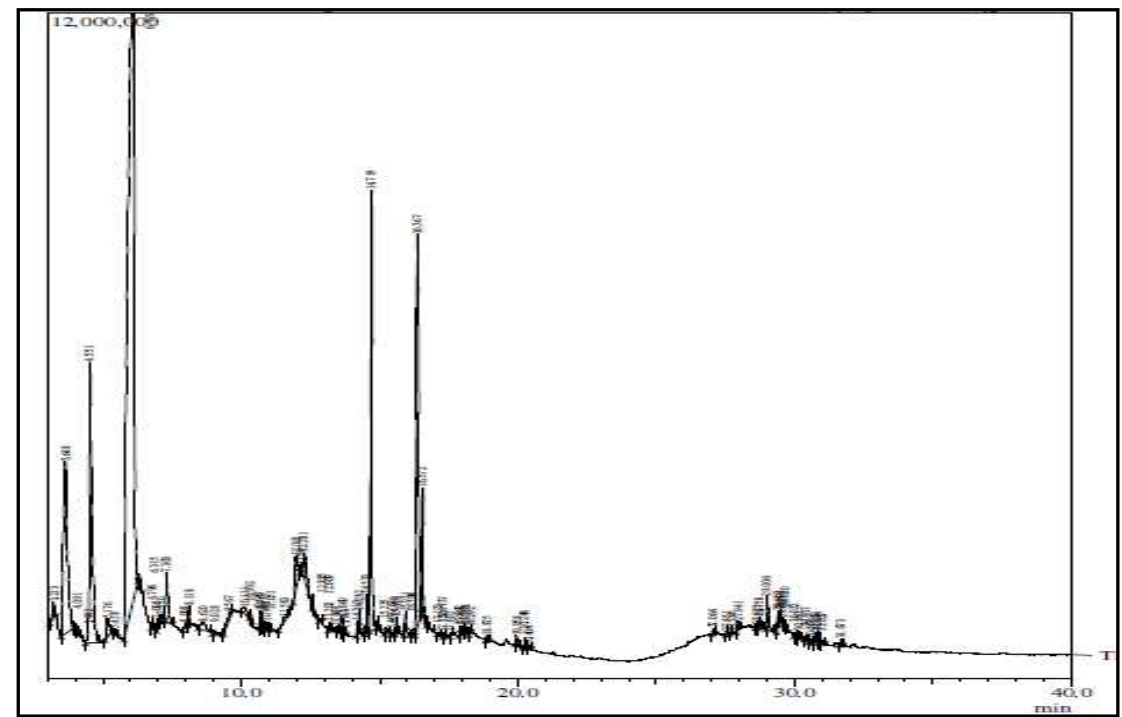

Fig. 11: GC-MS of nature grown roots of Chlorophytum borivilianum

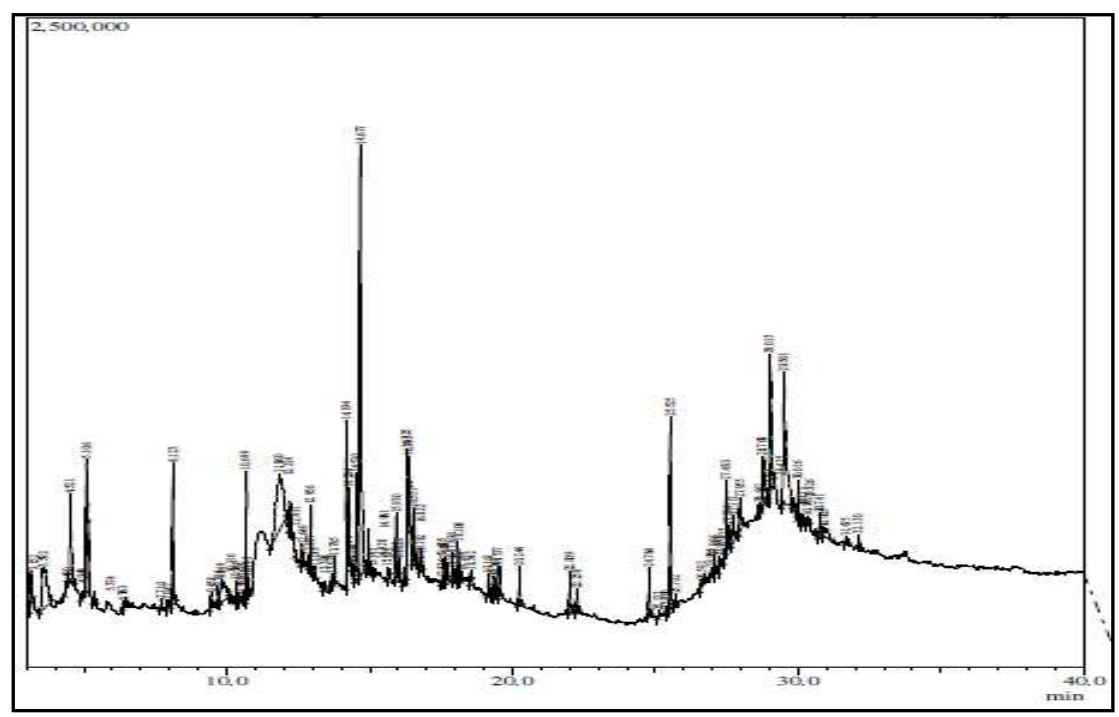

Fig. 12: GC-MS of in vitro regenerated roots of Chlorophytum borivilianum

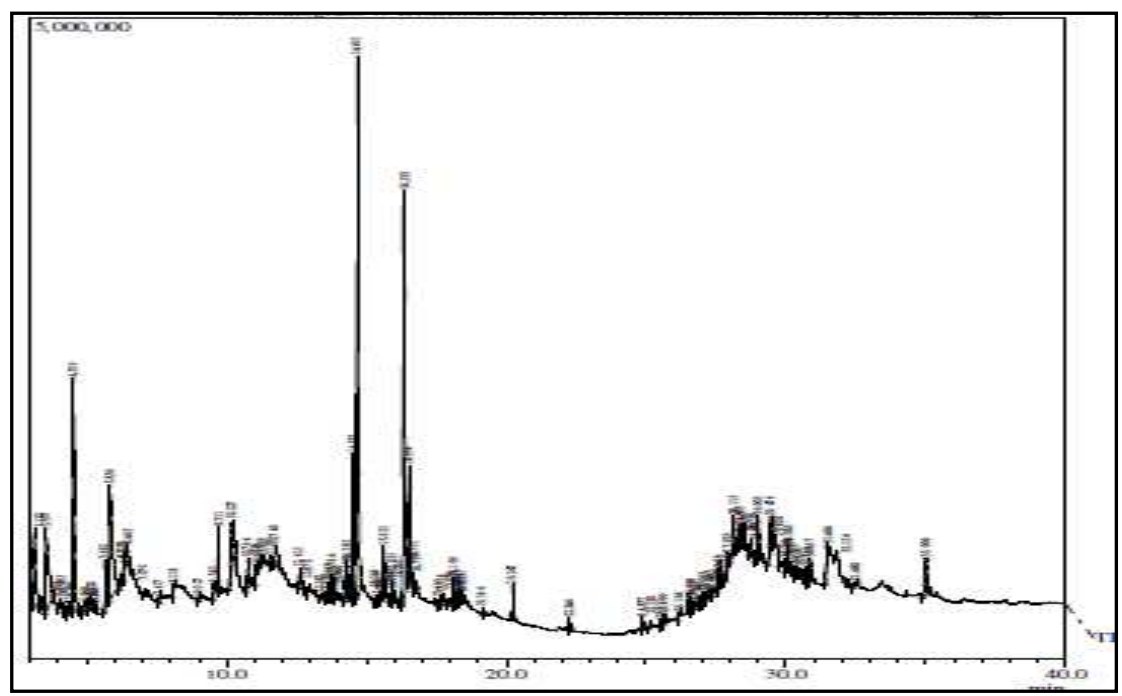

Fig. 13: GC-MS of callus of Chlorophytum borivilianum 


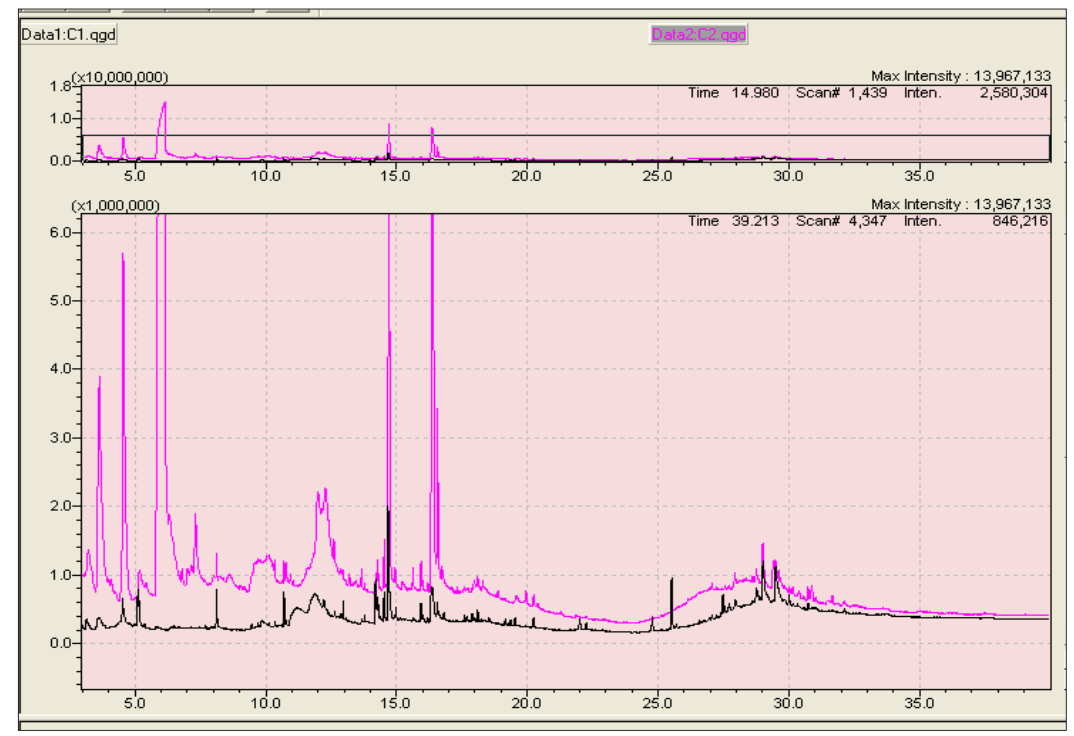

Fig. 14: An overlap chromatogram of GC of in vitro regenerated (hardened) and nature grown roots, C1 (Black) = in vitro regenerated root, $\mathrm{C} 2($ Pink $)=$ nature grown root

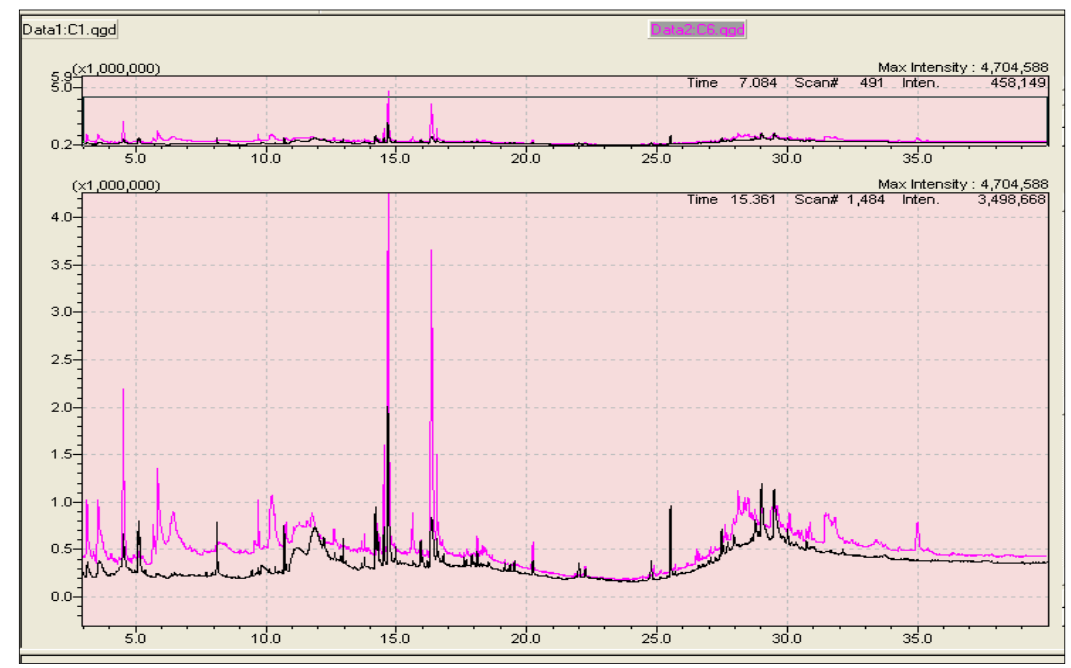

Fig. 15: An overlap chromatogram of GC of in vitro (hardened) regenerated roots and callus, $\mathrm{C1}$ (Black) = In vitro regenerated root, $\mathrm{C6}$ (Pink) = callus

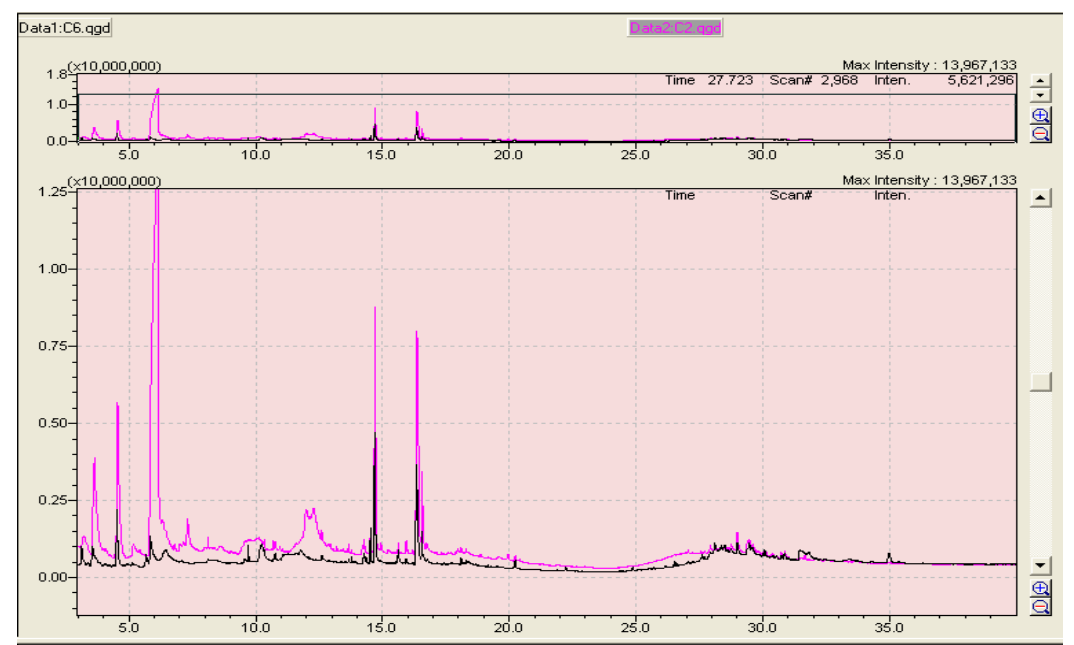

Fig. 16: An overlap chromatogram of GC of callus and nature grown roots, C6(Black) = callus, C2 (Pink) = Nature grown roots 


\section{DISCUSSION}

The detection of active principles in medicinal plants plays a strategic role in the phytochemical investigation of crude plant extracts and is very important with regards to their potential pharmacological effects [21-23].

Production of high-value natural products by cell and tissue cultures is a matter of great interest among scientists [24]. In cultures, factory type production of natural compounds can be carried out throughout the years, unaffected by season.

A comparative study of saponins in tubers of in vitro regenerated plantlets with tubers of nature grown plants showed that there was an enhancement in secondary metabolite content in tubers of micropropagated plants.

Chromatographic determination of saponins in plant material is still a challenge to the phytochemist. The unique chemical nature of saponins demands tedious and sophisticated techniques for their isolation, structure elucidation and analysis. The task of isolating saponins from plant material is complicated also by the occurrence of many closely related substances in plant tissues, and by the fact that most of the saponins lack a chromophore. There is no single method that can be recommended as a routine procedure for analysis of complex saponin mixtures. None of these methods provides a fingerprint, which allows the quality to be monitored. Also, none of them provides an adequate tool for the separation or preparative isolation of saponin components; a combination of several techniques is required obtain single standard compounds $[25,26]$. The estimation of secondary metabolites of $C$. borivilianum in the present investigation, therefore, proceeded using a combination of various techniques viz. TLC, spectrophotometric (colorimetric) estimation, HPLC, ESI-MS and GC-MS analysis.

The TLC analysis of the in vitro and nature grown roots and leaves of C. borivilianum in the present work showed the presence of saponins, flavonoids and alkaloids. The TLC of callus failed to show up any corresponding Rfs for flavonoids. The Rf values obtained in callus sample $0.73,0.58,0.56,0.52,0.44,0.22$ suggested the presence of a large number of glycosides. Yang et al. [27] reported similar RF values for steroidal saponins in the TLCs of Dioscorea spp.

Spectrophotometric methods are practical and simple, making them preferable for specification testing. Most frequently used colorants include Ehrlich or vanillin reagents and measurements are made at $\lambda$ $=515-560 \mathrm{~nm}$. Because of the weak absorbance of saponins, $\mathrm{a}$ colorimetric determination is used for their evaluation. To determine the amount of saponin in C. borivilianum extract, a spectrophotometric assay using Vanillin and Sulphuric acid was carried out. The result showed that the roots of in vitro grown plant possessed the highest saponin $(19.7 \mathrm{mg} / \mathrm{ml})$ content followed by that of callus $(12.5 \mathrm{mg} / \mathrm{ml})$ relative to the standard saponin used. The amount of saponin in the aqueous and alcoholic extracts of in vitro grown calli of $C$. borivilianum, by spectrophotometric method using Vanillin and Sulphuric acid was also studied by [28].

The HPLC analysis of the freshly harvested in vitro regenerated roots, callus and nature and hardened (six months) in vitro regenerated roots and leaves showed identical peaks at Retention time (RT) 2.10 with that of standard saponin (Sigma). There were some common peaks observed in the test tube grown roots, callus and nature grown and in vitro regenerated roots and leaves that were not observed in the standard saponin. The in vitro regenerated and nature grown roots and callus also showed similar RTs at 2.28, 2.26 and 2.27 respectively. Besides this, identical peaks were also observed at RT 2.98 and 2.95 for the in vitro regenerated and nature grown roots respectively. The leaves of nature grown and in vitro regenerated leaves and callus produced similar peaks at RTs 4.07 and 13.29.

Based on the literature by Li et al. the ESI-QTOF-MS of the steroidal saponins of $C$. borivilianum revealed the presence of molecular species in the positive ion mode. The diagnostic ions at $\mathrm{m} / \mathrm{z} 413$ confirmed that a substituent was attached on the steroid aglycone and its probable molecular formula to be $\mathrm{C}_{27} \mathrm{H}_{47} \mathrm{O}_{3}{ }^{+}$which was assumed to be a fission product of glycosides and water molecules. Besides, many peaks in the samples were found to be in common.
The fragmentation pattern of the nature grown root revealed the presence of glycosidic moieties, thereby producing peaks at $\mathrm{m} / \mathrm{z} 497$ and 533 found in the in vitro regenerated root. This observation is in accordance with the $\mathrm{m} / \mathrm{z}$ values for the compound chlorophytoside, in Chlorophytum laxum as reported by Gao et al. [29]. Acharya et al. [30] reported similar fragmentation of steroidal saponins in the nature grown root samples of $C$. borivilianum.

The GC-MS analysis showed the presence of a large number of phytosterols in the in vitro roots and callus extract; along with some of the medicinally important secondary metabolites like Taraxerone, $\beta$-Sitosterol and Lupenol (Triterpene). However, the in vitro roots showed the highest amount of all the three secondary products, with the remarkably higher percentage of $\beta$-Sitosterol $(8.16 \%)$ and Taraxerone (5.47\%). The higher amount of $\beta$-Sitosterol in the in vitro regenerated roots suggest the influence of tissue-culture protocols involving the use of different PGRs. Beta-sitosterol has been isolated from the cultured tissues of Terminalia chebula [31] as well as the callus of several plants viz. Morus alba [32], Vaccinium corymbosum [33], Cissus quadrangularis [34]. Bathoju and Giri [35] (2012) also reported the production of two important sapogenins; stimasterol and hecogenin from the in vitro regenerated root cultures of $C$. borivilianum. While, nature grown roots revealed the presence of sarasapogenin, the in vitro roots, on the other hand, showed the presence of squalene, which is an important precursor in the synthesis of steroidal compounds. The callus also revealed the presence of many important secondary metabolites of high medicinal importance like digitoxin, $\beta$-carotene and gamma sitosterol along with other phytosterols like ergosterol and stigmasterol. Incidentally, the in vitro regenerated roots showed a higher amount of ergosterol and stigmasterol as compared to the nature grown roots and callus.

Phytosterols are responsible for the permeability and fluidity of cellmembranes. Further, they act as a precursor of numerous other metabolites like glycoalkoloides and saponins [36]. The presence of the additional ethyl group branched on the alkyl chain of major phytosterols viz. sitosterol and stigmasterol, is proposed as reinforcing the membrane cohesion. The fine tuning of sterol structures thus appears to be the evolution response for plant adaptation to large temperature variations [37].

The in vitro regenerated roots revealed the presence of higher amount of $\alpha$-D-glucopyranoside and $D$-allose, albeit, the amount of $D$-allose in callus was slightly higher as compared to the hardened in vitro roots which had not been reported in the nature grown plant, which is evident from the overlap chromatograms of the root extracts and callus

Similar examples of high accumulation of secondary products in the in vitro cultures have been seen in many plants through the HPLC and GC-MS analysis viz. Lessertia frutescence [38], Rauwolfia serpentine [39] and Saussurea involucrate [40].

\section{CONCLUSION}

Presence of a large number of medicinally important secondary metabolites in Chlorophytum borivilianum has been widely studied. However, the reports on the enhanced production of these secondary metabolites from the in vitro cultures have been scarce. Based on the results established by HPLC, ESI-MS and GCMS it could be concluded that the production of secondary metabolites in in vitro cultures could be enhanced in plants of high medicinal importance irrespective of geography and seasonal variation or where natural sources are endangered, thus opening new avenues for phytopharmaceuticals.

\section{ACKNOWLEDGMENT}

The senior author acknowledges the financial assistance provided by the M. P. Council of Science and Technology, Bhopal, M. P., India

\section{AUTHORS CONTRIBUTIONS}

All experimental work was carried out by Jha A, whereas, Bansal Y. K. supervised them

\section{CONFLICT OF INTERESTS}

The authors declare that there is no conflict of interest regarding the publication of this paper. 


\section{REFERENCES}

1. Namdeo AG. Plant cell elicitation for production of secondary metabolites: a review. Pharmacogn Rev 2007;1:69-79.

2. Singh A, Chauhan HS. Safed musli (Chlorophytum borivilianum): distribution, biodiversity and cultivation. J Med Aromat Plant Sci 2003;25:712-9.

3. Kothari SK. Safed musli (Chlorophytum borivilianum) revisited. J Med Aromat Plant Sci 2004;26:60-3.

4. Thakur M, Dixit VK. Fructan; the polymer with unexplored potential. Indian Pharm 2005;4:7-12.

5. Sreevidya N, Govindarajan R, Vijayakuma M, Thakur M, Dixit VK, Mehrotra S, et al. Action of fructo-oligo polysaccharide fraction of Chlorophytum borivilianum against streptozotocin induced oxidative stress. Planta Med 2006;72:1421-4.

6. Thakur M, Dixit VK. A review on some important medicinal plants of Chlorophytum spp. Pharmacogn Rev 2008;2:168-72.

7. Purohit SS, Prajapati ND. Local heritage with global importance. AGROBIOS News Lett 2003;1:7-8.

8. Kemat N, Kadir MA, Abdullah NAP, Ashraf F. Rapid multiplication of safed musli (Chlorophytum borivilianum) through shoot proliferation. Afr J Biotechnol 2010;9:4595-4600.

9. Maiti S, Geetha KA. Safed Musli. Published by indian council of agricultural research (ICAR) New Delhi; 2009. p. 18-39.

10. Dave A, Bilochi G, Purohit SD. Scaling-up production and field performance of micropropagated medicinal herb 'safed musli' (Chlorophytum borivilianum). In vitro Cell Dev Biol: Plant 2003;39:419-24.

11. Basu S, Jha T. In vitro propagation of the rare medicinal plant Chlorophytum borivilianum Sant et. Fern. In: Proc Nat Symp of Plant Biotechnology; 2007. p. 285-9.

12. Rizvi MZ, Kukreja AK, Knanuja SPS. In vitro culture of Chlorophytum borivilianum Sant et Fernand in liquid culture medium as a cost-effective measure. Curr Sci 2007;92:87-90.

13. Jha A, Bansal YK. High frequency direct somatic embryogenesis from the juvenile shoot buds of Chlorophytum borivilianum Sant. Et Fernand and production of artificial seeds. Int J Pharm Sci Res 2016;7:2040-9.

14. Obadoni BO, Ochuko PO. Phytochemical studies and comparative efficacy of crude extracts of some Homostatic plants in Edo and Delta states of Nigeria. Global J Pure Appl Sci 2010;8:203-8.

15. Haque R, Saha S, Bera T. A peer reviewed of general literature on Chlorophytum borivilianum commercial medicinal plant. Int J Drug Dev Res 2011;3:140-55.

16. Harborne JB. Twenty-five years of chemical ecology. Nat Prod Rep 2001;18:361-79.

17. Evans WC. In: Evans WC, Trease GE. editors. Trease and Evans' Pharmacognosy. $14^{\text {th }}$ ed. London: WB Saunders company ltd; 1996. p. 612.

18. Hiai S, Oura H, Nakajima T. Color reaction of some sapogenins with vanillin and sulfuric acid. Planta Med 1976;29:116-22.

19. Hamburger M, Slacanin I, Hostettmann K, Dyatmiko W. Acetylated saponins with molluscicidal activity from Sapindus rarak: Unambiguous structure determination by proton nuclear magnetic resonance and quantitative analysis. Phytochem Anal 1992;3:231-7.

20. Li R, Zhou Y, Wu Z, Ding L. ESI-QTOF-MS/MS and APCI-ITMS/MS analysis of steroid saponins from the rhizomes of Dioscorea panthaica. J Mass Spectrom 2006;41:1-22.

21. Pascual ME, Carretero ME, Slowing KV, Villar A. Simplified screening by TLC of plant drugs. Pharm Biol 2002;40:139-43.

22. Fidrianny I, Winarsih S, Ruslan K. Phytochemical content and antioxidant potential of different organs of eggplant (Solanum melongena l.) grown in west Java-Indonesia. Asian J Pharm Clin Res 2017;10:144-9.

23. Paramasivam I, Simran Sinsinwar S, Muthuraman MS Phytopharmacological properties of Melothria maderaspatana: a review. Asian J Pharm Clin Res 2017;10:34-6.

24. Ramachandra Rao S, Ravishankar GA. Plant cell cultures: chemical factories of secondary metabolites. Biotechnol Adv 2002;20:101-53.

25. Muir AD, Ballantyne KD, Hall TW. LCMS and LC-MS/MS analysis of saponins and sapogenins-comparison of ionization techniques and their usefulness in compound identification. In: Saponins in Food, Feedstuffs and Medicinal Plants, Annual Proceedings of the Phytochemical Society; 2000. p. 35-42.

26. Schopke T. Non-NMR methods for structure elucidation of saponins. In: Saponins in Food, Feedstuffs and Medicinal Plants. Annual Proceedings of the Phytochemical Society; 2000. p. 106-13.

27. Yang DJ, Lu TJ, Hwang LS. Isolation and identification of steroidal saponins in Taiwanese yam cultivar (Dioscorea pseudojaponica Yamamota). J Agric Food Chem 2003; 51:6438-44.

28. Kapur S, Pal A, Gurjar S, Pavan VVS, Sharad S. Isolation and characterization of secondary metabolites "saponins" from the explants of Indian medicinal plant Chlorophytum borivilianum. Int J Pharm Front Res 2011;1:14-22.

29. Gao YH, Mei QX, Wu HF, Diao YM, Peng XS, Zhang RF. Chlorophytoside A, a new labdane diterpene glycoside from Chlorophytum laxum. Chin Chem Lett 2005;16:925-7.

30. Acharya D, Mitaine-Offer AC, Kaushik N, Miyamoto T, Lacaille Dubois MA. Furostane-type steroidal saponins from the roots of Chlorophytum borivilianum. Helvetica Chim Acta 2008;91:2262-9.

31. Sharma A, Suchitra M, Anirudha R. Quantitative estimation of $\beta$ sitosterol and stigmasterol in vivo and in vitro Terminalia chebula Ritz. Int Res J Pharmacol 2012;2:115-6.

32. Kulkarni DD, Ghugale DD, Narsimhan R. Chemical investigation of plant tissues grown in vitro: isolation of beta-sitosterol from Morus alba (mulberry) callus tissue. Indian J Exp Biol 1970;8:347.

33. Migas P, Luczkiewicz M, Cisowski W. The influence of auxins on the biosynthesis of isoprene derivatives in callus cultures of Vaccinium corymbosum var. blue crop. Zeitschrift Naturforschung 2006;61:565-70.

34. Sharma N, Nathawat RS, Gour K, Patni V. Establishment of callus tissue and effect of growth regulators on enhanced sterol production in Cissus quadrangularis L. Int J Pharmacol 2011;7:653-8.

35. Bathoju G, Giri A. Production of stigmasterol and hecogenin from in vitro cultures of Chlorophytum borivilianum. J Pharmacog 2012;3:101-3.

36. Piironen V, Lindsay DG, Miettinen TA, Toivo J, Lampi AM. Plant sterols: biosynthesis, biological function and their importance to human nutrition. J Sci Food Agric 2000;80:939-66.

37. Dufourc EJ. The role of phytosterols in plant adaptation to temperature. Plant Signal Behav 2008;3:133-4.

38. Shaik S, Singh N, Nicholas A. HPLC and GC analyses of in vitro grown leaves of cancer bush Lessertia frutescens (Sutherlandia) reveals higher yields of bioactive compounds. Plant Cell Tiss Organ Cult 2011;105:431-8.

39. Roja PC, Heble MR. Indole alkaloids in clonal propagation of Rauvolfia serpentina benth ex. Kurz. Plant Cell Tiss Organ Cult 1996;44:111-5.

40. Guo B, Gao M, Liu CZ. In vitro propagation of an endangered medicinal plant Saussurea involucrate Kar. Et Kir. Plant Cell Rep 2007;26:261-5 